\title{
Hypolipidemic Effect of Triphala in Experimentally Induced Hypercholesteremic Rats
}

\author{
Selvaraj SARAVANAN, Ramasundaram SRIKUMAR, Sundaramahalingam MANIKANDAN, \\ Narayanaperumal JEYA PARTHASARATHY, and Rathinasamy SHEELA DEVI* \\ Department of Physiology, Dr. ALM. PG. Institute of Basic Medical Sciences, University of Madras, \\ Taramani Campus, Chennai, Tamilnadu, India
}

(Received August 22, 2006; Accepted November 22, 2006)

\begin{abstract}
Hypercholesteremia is one of the risk factors for coronary artery disease. The present study highlights the efficacy of Ayurvedic herbal formulation Triphala (Terminalia chebula, Terminalia belerica, and Emblica officinalis) on total cholesterol, Low density lipoprotein (LDL), Very low density lipoprotein (VLDL), High density lipoprotein (HDL) and free fatty acid in experimentally induced hypercholesteremic rats. Four groups of rats were employed namely control, Triphala treated, hypercholesterolemia rats $(4 \%$ Cholesterol $+1 \%$ cholic acid + egg yolk) and Triphala pre-treatment in hypercholesteremic rats. Results showed significant increase in the total cholesterol, LDL, VLDL, and free fatty acid in hypercholesteremic rats were significantly reduced in Triphala treated hypercholesteremic rats. The data demonstrated that Triphala formulation was associated with hypolipidemic effects on the experimentally induced hypercholesteremic rats.
\end{abstract}

Key words_- cholesterol; lipid profile; triphala

\section{INTRODUCTION}

Coronary artery disease (CAD) is one of the most important causes of death all over the world. $\left.{ }^{1}\right)$ Hypercholesteremia is one of the risk factors for CAD. The increased blood levels of total cholesterol, low density lipoprotein (LDL) and very low density lipoprotein (VLDL) cholesterol as well as lowered levels of high density lipoprotein (HDL) cholesterol has been identified in the development of hypercholesterolemia. ${ }^{2)}$ People who are predisposed to a combination of risk factors (dietary habits, genetic susceptibility, etc.) are more prone to develop hypercholesterolemia. Besides stress, sedentary habits, use of tobacco and alcohol are reported to have an additive effect in contributing to development of hypercholesterolemia. ${ }^{3)}$ The initial steps in the prevention of hypercholesterolemia is the modification of the nutritional regime with a diet low in fats and saturated fatty acids and rich in crude fibers. Cholesterol biosynthesis in the body is mainly regulated in the liver by the enzyme 3-hydroxy-3-methylglutaryl-coenzyme A (HMGCoA) reductase (HMGR). ${ }^{4)}$ Inhibition of this enzyme has proven to be the most efficient therapy for hyperlipidemia, since the enzymatic transformation of HMG-CoA to mevalonate represents one of the

\footnotetext{
*e-mail: drsheeladevi@yahoo.com
}

key steps in the metabolic pathway toward the biosynthesis of isoprenoids and sterols, such as cholesterol. ${ }^{5}$

Plants and herbs in the Indian system of medicine have been reported to be beneficial against hypercholesterolemia. ${ }^{6,7)}$ Triphala is a traditional Ayurvedic herbal formulation, consisting equal parts of three medicinal plants namely Terminalia chebula, Terminalia belerica and Emblica officinalis. Triphala, is considered as a 'tridoshic rasayan', having balancing and rejuvenating effects on the three constitutional elements that govern human life i.e., Vata, Pitta and Kapha by Charka (1,500 B.C.) in the Charaka Samihita ${ }^{8)}$ Triphala has been reported to possess antioxidant rich herbal formulation, ${ }^{9}$ ) improves the mental faculties ${ }^{10}$ ) and also assists in the weight loss. ${ }^{11)}$ Triphala contains about $20 \%$ tannins of both condensed and hydrolysable type. Other constituents identified in the fruit include lipids, sitosterol, saponins, gallic and ellagic acids, cardiac glycoside and various carbohydrates. ${ }^{12)}$ Fruits of Triphala are claimed to have various biological activities such as, exerts a marked heart-protective and cardio-tonic effect, improves digestion, ${ }^{13)}$ improves liver function and hepatoprotective. ${ }^{14)}$

The present study was undertaken to evaluate the hypolipidemic activity of Triphala on total cholesterol, free fatty acid, HDL, LDL and VLDL in 
experimentally induced hypercholesteremic rats.

\section{MATERIALS AND METHODS}

Drug and Dosage Fruits of Triphala (T. chebula, T. belerica, and E. officinalis) were collected and authenticated from The Chief Botanist, TamilNadu Medicinal plant farms and Herbal Medicine Corporation (TAMPCOL) Ltd., Chennai, India. The seedless fruits were dried under shade and powdered. Equal proportion $(1: 1: 1)$ of powder from each fruits were mixed and used for this study. Triphala powder was mixed in normal saline $(1 \mathrm{ml})$ and administered intragastrically at the dose of $1 \mathrm{~g} / \mathrm{kg}$ b.w. for 48 days. ${ }^{15)}$

Experimental Groups Animals, three-monthold male albino rats (Wistar strain, 170-190 g) were selected for this study and used with the approval of Institute's Animal Ethics Committee (IAEC No. 08/ 006/02). Animals were housed in a well-ventilated animal unit with normal daylight $(12 \mathrm{~h}$ light/dark cycle, lights on at $07: 00 \mathrm{~h}$ ). The animals were fed with standard food (Hindustan Ltd.) and water ad libitum. The animals were divided into four groups $(n=$ 6) and the following treatments were given simultaneously to the concerned groups for forty eight days.

Group-I : Animal received standard diet + saline $(1 \mathrm{ml})$ intragrastrically for 48 days.

Group-II : Animal received standard diet + Triphala supplements $(1 \mathrm{~g} / \mathrm{kg}$ b.w.) for 48 days.

Group-III : Animal received Cholesterol (4\% Cholesterol $+1 \%$ cholic acid + egg yolk) for 30 days. ${ }^{16)}$

Group-IV : Animal received Triphala supplements ( $1 \mathrm{~g} / \mathrm{kg} \mathrm{b.w.)} \mathrm{for} 48$ days along with cholesterol from 18 th day of the regimen.

Estimation of Biochemical Parameters After the experiment regimen, the animals were demanded to overnight fasting but were permitted for water $a d$ libitum. From all group animals $2 \mathrm{ml}$ blood samples were drawn using jugular vein puncture, centrifuged, the plasma was collected and stored $-80^{\circ} \mathrm{C}$ until used for the biochemical estimation.

Plasma total cholesterol level was estimated by determining color development of plasma and ferric acetate-uranium acetate reagent mixture with sulfuric acid-ferrous sulfate reagent was read at $530 \backslash \mathrm{nm} .{ }^{17)}$ Plasma triglycerides level was estimated by the method of Foster and Dunn. ${ }^{18)}$ Mixture of plasma, isopropanol and alumina was centrifuged, to the supernatant saponification reagent was added and boiled at $65^{\circ} \mathrm{C}$ for 15 minutes. Further, sodium metaperiodate and acetyl acetone were added, mixed well and kept in water bath for 30 minutes. Tubes were allowed to cool for room temperature and color was read at $430 \mathrm{~nm}$. Triolein used as standard and plasma triglycerides level was expressed as $\mathrm{mg} / \mathrm{dl}$ of plasma. Plasma was added with heparin manganese chloride in a test tube, followed by incubation in an ice bath for 30 minutes. After incubation, tubes were centrifuged for 30 minutes. The supernatant contained the HDL fraction was assayed according to the method of Parekh and Jung. ${ }^{17)}$ LDL and VLDL cholesterol was calculated according to Friedewald's formula. ${ }^{19)}$ Free fatty acids level was estimated by the method of Hron and Menahan (1981) using the modifying color reagent of Itaya. ${ }^{20)}$ Haematoxylin and eosin stain (H\&E) for liver has been used in this study was according to Culling (1972).21)

Statistical Analysis Data are presented as Mean \pm S.D. of six animals. Statistical evaluation was done using the one-way analysis of variance (ANOVA) using SPSS version 10.0 (SPSS, Cary, NC, USA).

Table 1. Effect of Triphala on plasma total cholesterol, triglycerides, Free Fatty Acid, HDL, LDL and VLDL, in Hypercholesteremic Induced Male Albino Rats

\begin{tabular}{lcccc}
\hline \multicolumn{1}{c}{ Parameters } & Control & Triphala alone & Hypercholesteremia & Hypercholesteremia + Triphala \\
\hline Total cholesterol $(\mathrm{mg} / \mathrm{dl})$ & $70.24 \pm 7.90$ & $75 \pm 5.33^{\sharp}$ & $142.09 \pm 11.71^{*}$ & $69.80 \pm 4.06^{\sharp}$ \\
Triglycerides $(\mathrm{mg} / \mathrm{dl})$ & $87.40 \pm 4.55$ & $63.14 \pm 8.98^{*}, \sharp$ & $213.30 \pm 14.90^{*}$ & $94.55 \pm 3.03^{\sharp}$ \\
Free fatty acid $(\mathrm{mg} / \mathrm{dl})$ & $22.86 \pm 1.55$ & $22.89 \pm 3.07^{\sharp}$ & $56.27 \pm 9.76^{*}$ & $20.35 \pm 1.30^{\sharp}$ \\
HDL $(\mathrm{mg} / \mathrm{dl})$ & $31.82 \pm 4.18$ & $39.84 \pm 5.31$ & $35.42 \pm 8.14$ & $38.04 \pm 5.64$ \\
LDL $(\mathrm{mg} / \mathrm{dl})$ & $20.94 \pm 3.48$ & $22.53 \pm 1.79^{\sharp}$ & $64.01 \pm 9.28^{*}$ & $13.86 \pm 2.73^{\sharp}$ \\
VLDL $(\mathrm{mg} / \mathrm{dl})$ & $17.48 \pm 0.91$ & $12.63 \pm 1.79^{*}, \sharp$ & $42.66 \pm 2.98^{*}$ & $18.91 \pm 0.61^{\sharp}$ \\
\hline
\end{tabular}

Values are expressed as Mean \pm SD of six animals. The symbols represent statistical significance : ${ }^{*},{ }^{\sharp},=p<0.05 .{ }^{*}$ Significant differences vs. control, ${ }^{*}$ Significant differences vs. hypercholesteremia. 


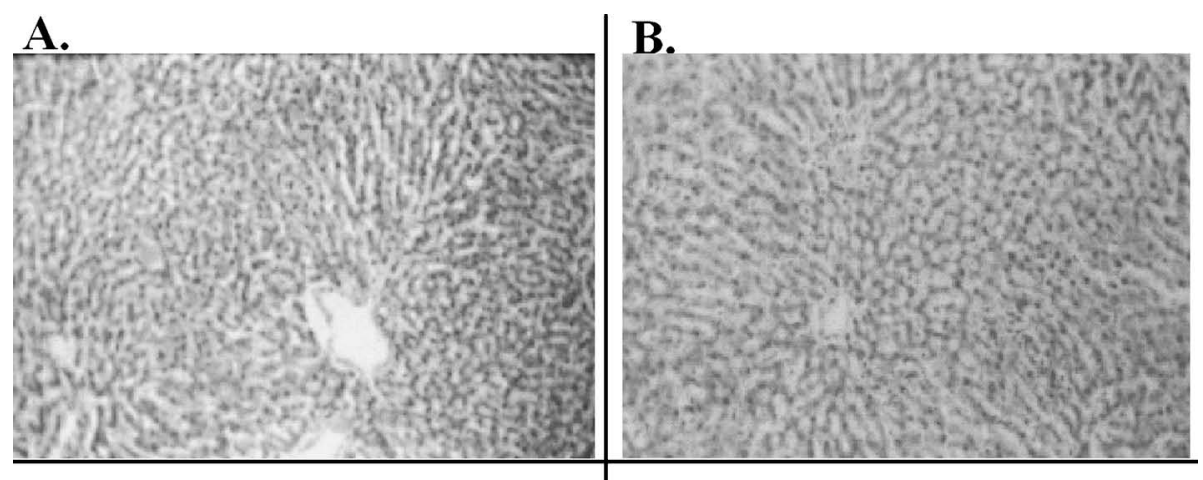

Fig. 1. Illustrates H \& E Stained Parenchymal Cell and Sinusoidal Pattern of Rats Liver (10X) in Control Rat Liver Cell Morphology (A), Triphala Administration for 48 Days (B)

Both control and Triphala treated rats showed similar pattern of liver parenchyma and sinusoidal cells.

When there was a significant difference, Tukey's multiple comparisons were performed by fixing the significance level at $p<0.05$.

\section{RESULTS AND DISCUSSION}

The present study reveals the hypolipidemic activity of Triphala in experimentally induced hypercholesteremic rats. The study showed administration of Triphala ( $1 \mathrm{~g} / \mathrm{kg} /$ body weight) for 48 days, triglycerides and VLDL was significantly reduced (Group II) (Table 1). With our previous report the animal body weight remains unaltered during forty eight days of Triphala administration, ${ }^{15)}$ hence significant reductions in the triglyceride and VLDL in Triphala treated rats (Group II) were not due to any overt toxicity. In addition, histopathological study of rat liver showed parenchyma and sinusoidal pattern in Triphala treated group (Fig. 1(B)) was similar with that of control group (Fig. 1(A)). An increase in the concentration of lipids results in liberation of lysosome and trigger cells degeneration. Major component of total cholesterol is LDL which is directly related to CAD and increase in the free fatty acid level leads to myocardial oxygen consumption. ${ }^{22)}$ Rats fed with cholesterol (Group III) showed significant increase in total cholesterol, triglycerides, free fatty acids, LDL and VLDL conforming that cholesterol fed $(4 \%$ Cholesterol $+1 \%$ cholic acid + egg yolk) in this study induced hypercholesteremia experimentally. ${ }^{16)}$ The notable changes in the HDL levels in plasma were not statistically influenced by either in Triphala supplements or in hypercholesteremic rats. Triphala formulation is rich in soluble fiber which improves digestion, regulates elimination without caus- ing any laxative dependency, and rich in antioxidant. ${ }^{9)}$ In the present study significant decrease in the total cholesterol, triglycerides, free fatty acids, LDL and VLDL in Triphala treated hypercholesteremic rats (Group VI) may be to reduction in the absorption of cholesterol. ${ }^{23)}$ Oral administration of T. chebula reported to increase gastric emptying, might be the reason for decrease in the cholesterol absorption. ${ }^{24)}$

Drugs like Statins administration results in reduction of LDL cholesterol by inhibiting HMG-CoA reductase in the liver. In our study, we have observed reduction in the LDL cholesterol in hyperlipidimic rats after Triphala administration. This may be due to, at lease in a part, the HMG-CoA reductase inhibitory action of Triphala. Nevertheless, the exact mechanism of action remains to be elucidated before considering an eventual human treatment.

Acknowledgments The authors are grateful to Late Prof. A. Namasivayam for his valuable guidance and the University Grant Commission (UGC-Herbal Sciences. HS.21).

\section{REFERENCES}

1) Gambhir D. S., Gambhir J. K., Sudha R., Indian Heart J., 52, 515-516 (2001).

2) Ross R. N., Eng. J. Med., 340, 115-126 (1999).

3) Ashakumary A., Vijayammal P. L., Indian J. Exp. Biol., 31, 270-274 (1993).

4) Goldstein J. L., Brown M. S., Nature, 343, 425 (1990).

5) Jakobisiak M., Golab J., Int. J. Oncol., 23, 
2055 (2003).

6) Gunde-Cimerman N., Int. J. Med. Mushrooms, 1, 69-80 (1999).

7) Ryong L. H., Tertov V. V., Drug. Dev. Res., 17, 109-117 (1989).

8) Sharma R. K., Dash B., "Carka Samhita" Vol. II, Chowkamba Sanskrit Series Office, India, 1998.

9) Srikumar R., Jeya Parthasarathy N., Manikandan S., Sathya Narayanan G., Sheeladevi R., Mol. Cell. Biochem., 283, 67-74 (2006) .

10) Antarkar D. S., Vaidya A. B., Doshi J. C., Athavale A. V., Vinchoo K.S., Natekar M. R., Tathed P. S., Ramesh V., Kale N., Indian J. Med. Res., 72, 588-593 (1980).

11) Hashimoto M., Nakajima Y., Jpn. Kokai. Tokkyo. Koho. JP., 09, 227-398 (1997).

12) Reddy V. R. C., Kumari R., Reddy S. V., Anzeem M. A., Prabhakar M.G., Appa Rao A. V. N., Fitoterapia, 61, 517-525 (1990).

13) Chawla Y. K., Indian J. Med. Res., 76, 95-98 (1982).

14) Gulati R., Agarwal S., Agarwal S. S., Indian J. Exp. Biol., 33., 261-268 (1995).

15) Srikumar R., Jeya Parthasarathy N., Sheela
Devi R., Biol. Pharm. Bull., 28., 1398-1403 (2005).

16) Deepa P. R., Varalakshmi P., Mol. Cell. Biochem., 254, 111-116 (2003).

17) Parekh A. C., Jung D. H., Anal. Chem., 42, 1423-1427 (1970).

18) Foster L. B., Dunn R. T., Clin. Chem., 19, 338-340 (1973).

19) Friedewald W. T., Robert I., Levy and Donald S., Clin. Chem., 18, 499-502 (1972).

20) Hron W. T., Menahan L. A., J. Lipid. Res., 22, 377-381 (1981).

21) Culling C. F. A., "Handbook of Histopathological and Histochemical Techniques," 3rd ed., Butterworths London, 1972.

22) Peterson L. R., Herrero P., Schechtman K. B., Racette S. B., Waggoner A. D., KisrievaWare Z., Dence C., Klein S., Marsala J., Meyer T., Gropler RJ., Circulation, 109, 21912196 (2004).

23) Bobek P., Ginter E., Jurcovicova M., Ozdin L., Mekinova D., Ann. Nutri. Met., 35, 191195 (1991).

24) Jason Kirby R., Philip N., Howles and David Y., Hui, J. Lipid. Res., 45, 89-98 (2004). 